\title{
In and Ga Codoped ZnO Film as a Front Electrode for Thin Film Silicon Solar Cells
}

\author{
Duy Phong Pham, ${ }^{1}$ Huu Truong Nguyen, ${ }^{2}$ Bach Thang Phan, ${ }^{2,3}$ Thi My Dung Cao, ${ }^{3}$ \\ Van Dung Hoang, ${ }^{2}$ Vinh Ai Dao, ${ }^{1}$ Junsin Yi, ${ }^{1}$ and Cao Vinh Tran ${ }^{2}$ \\ ${ }^{1}$ College of Information and Communication Engineering, Sungkyunkwan University, 300 Cheoncheon-dong, Jangan-gu, \\ Suwon 440-746, Republic of Korea \\ ${ }^{2}$ Laboratory of Advanced Materials, University of Science, 227 Nguyen Van Cu Street, 5th District, Ho Chi Minh City 70000, Vietnam \\ ${ }^{3}$ Faculty of Materials Science, University of Science, 227 Nguyen Van Cu Street, 5th District, Ho Chi Minh City 70000, Vietnam
}

Correspondence should be addressed to Junsin Yi; yi@yurim.skku.ac.kr and Cao Vinh Tran; tcvinh@hcmus.edu.vn

Received 21 October 2014; Accepted 7 December 2014; Published 28 December 2014

Academic Editor: Markus R. Wagner

Copyright (C) 2014 Duy Phong Pham et al. This is an open access article distributed under the Creative Commons Attribution License, which permits unrestricted use, distribution, and reproduction in any medium, provided the original work is properly cited.

Doped $\mathrm{ZnO}$ thin films have attracted much attention in the research community as front-contact transparent conducting electrodes in thin film silicon solar cells. The prerequisite in both low resistivity and high transmittance in visible and near-infrared region for hydrogenated microcrystalline or amorphous/microcrystalline tandem thin film silicon solar cells has promoted further improvements of this material. In this work, we propose the combination of major Ga and minor In impurities codoped in $\mathrm{ZnO}$ film (IGZO) to improve the film optoelectronic properties. A wide range of $\mathrm{Ga}$ and In contents in sputtering targets was explored to find optimum optical and electrical properties of deposited films. The results show that an appropriate combination of In and Ga atoms in $\mathrm{ZnO}$ material, followed by in-air thermal annealing process, can enhance the crystallization, conductivity, and transmittance of IGZO thin films, which can be well used as front-contact electrodes in thin film silicon solar cells.

\section{Introduction}

Thin film silicon solar cells (TFS-SCs) have received much attention due to their advantages such as flexibility, large area deposition, and low-cost manufacturing [1-3]. Up till now, despite the many advantages of thin film solar cells, their low efficiency is still a drawback that must be improved. In the recent years, much effort has been put in enhancing TFSSC efficiency by many different ways [4-6]. One of these is to improve the quality of transparent conducting oxide (TCO) electrode layer, an integral part in the structure of thin film solar cells [7]. TCO electrode layer usually plays an essential role as a front electrode and as a part of the backside reflector. Upon use as front electrode for hydrogenated microcrystalline $(\mu \mathrm{c}-\mathrm{Si}: \mathrm{H})$ or amorphous/microcrystalline tandem (a-Si:H/ $\mu \mathrm{c}-\mathrm{Si}: \mathrm{H}$ "micromorph") TFS-SCs in order to improve cell efficiency, TCOs are required to have both a high transparency in visible as well as near-infrared (NIR) region, where the solar cell is operating, and a high electrical conductivity [8]. Unfortunately, these two characteristics depend adversely on each other. For TCO electrodes, the conductivity substantially depends on the carrier concentration and mobility. The high conductivity of TCO films normally desires a high carrier concentration, caused by intrinsic defects or external doping. Currently, the carrier concentration in well-developed TCOs is in the range of $10^{20}-10^{21} \mathrm{~cm}^{-3}$. These high values induce a strong decrease in the transmittance in NIR region due to the free-carrier absorption so that these TCOs are not suitable for front transparent electrodes in solar cells [9]. The combination of high conductivity and high transparency in both visible and NIR region is a key issue for TCO material and the enhancement of carrier mobility of TCO is a way of attaining this goal [10].

Among TCO thin films, n-type doped $\mathrm{ZnO}$ thin films have gained much interest in recent years due to their low resistivity, high transmittance, nontoxicity, good stability in hydrogen plasma processes, and resource availability [11, 12]. 
TABLE 1: The $\mathrm{ZnO}$ targets with various percentages of $\mathrm{Ga}$ and In atoms.

\begin{tabular}{ccccccc}
\hline \multicolumn{2}{c}{ Target } & A & B & C & D & E \\
\hline \multirow{2}{*}{ Impurity } & at\% In & 0 & 0.1 & 0.3 & 0.5 & 1 \\
& at\% Ga & 5 & 4.9 & 4.7 & 4.5 & 4.0 \\
\hline
\end{tabular}

With the doping of group III elements such as $\mathrm{B}, \mathrm{Al}, \mathrm{Ga}$, and $\mathrm{In}$, the doped $\mathrm{ZnO}$ films become an attractive candidate for replacing tin oxide $\left(\mathrm{SnO}_{2}\right)$ or Indium tin oxide (ITO) as transparent conducting electrodes in TFS-SCs $[13,14]$. Among the elements listed above, $\mathrm{Ga}$ is the most successful and efficient dopant due to its advantages such as good lattice matching with $\mathrm{ZnO}$ lattice even for the case of high Ga concentrations, less reactive and more resistant to oxidation than $\mathrm{Al}$ element, which has been used as a dopant in most of the research works based on $\mathrm{ZnO}$ [15].

In this study, we tend to prepare Ga-doped $\mathrm{ZnO}$ (GZO) films as front-contact electrode for TFS-SCs with low resistivity and high transparency in both visible and near-IR (NIR) region. In particular, we find that a small amount of additional In atoms can improve electrical property of GZO films by enhancing the carrier mobility without any change in high transparency of films. Effect of minor In impurities on fostering electrical property of GZO films is systematically investigated by changing various doping contents in sputtering targets and film thicknesses.

\section{Experiment}

Doped $\mathrm{ZnO}$ targets with various codoping percentages of Indium and Gallium atoms, as listed in Table 1, were prepared using a conventional powder sintering process. The $\mathrm{Ga}$ and In codoped $\mathrm{ZnO}$ (IGZO) thin films, sputtered from the obtained targets, were deposited on glass substrates (Marienfeld, Germany) using dc magnetron sputtering. The films were deposited in pure Ar gas plasma with a sputtering pressure of $0.4 \mathrm{~Pa}$ and power density of $1.32 \mathrm{~W} / \mathrm{cm}^{2}$. The substrate temperature $300^{\circ} \mathrm{C}$ and the target-substrate distance $5 \mathrm{~cm}$ are constant during deposition. The thicknesses of films ranging from $500 \mathrm{~nm}$ to $2000 \mathrm{~nm}$ were determined by using a stylus profiler (Dektak 6M). Postanneals to foster crystalline quality were carried out in a VMK 1800 Linn furnace at $450-500^{\circ} \mathrm{C}$ in air for 2 hours. The electrical properties of films were characterized using Hall measurements (Ecopia HMS-3000) and the four-point probe. The optical spectra were recorded using UV-Vis Jasco V-530 in the wavelength range of $200 \mathrm{~nm}$ to $1100 \mathrm{~nm}$. X-ray diffraction (XRD) patterns to determine the crystalline structure of the samples were obtained by using a D8 ADVANCE-BRUKER system with $\mathrm{Cu} \mathrm{K} \alpha$ primary $\mathrm{X}$-rays. The element components in film were identified by energy dispersive X-ray (EDX) spectroscopy using 7593-h HORIBA system.

\section{Results and Discussion}

Table 1 shows various percentages of In and $\mathrm{Ga}$ atoms codoped in $\mathrm{ZnO}$ targets, represented by symbols A-E. $\mathrm{ZnO}$ target with Ga content of 5 at\% is known to be a suitable one to attain GZO thin films having high conductivity and transparency. The films sputtered from the targets also correspond to symbols A-E for easy reference. X-ray diffraction patterns of these films are shown in Figure 1(a). All the films have a prominent $\mathrm{ZnO}$ (002) peak, indicating the typical hexagonal wurtzite structure of $\mathrm{ZnO}$ material. No crystalline phases of $\mathrm{In}_{2} \mathrm{O}_{3}$ and $\mathrm{Ga}_{2} \mathrm{O}_{3}$ compounds were observed in the $\mathrm{X}$-ray patterns, suggesting that $\mathrm{Ga}^{3+}$ or $\mathrm{In}^{3+}$ ions probably replaced $\mathrm{Zn}^{2+}$ or located in the interstitial sites in the $\mathrm{ZnO}$ lattices or segregated into the noncrystalline region in the grain boundaries [16]. The strongest (002) peak intensity is observed for sample B that deposited from sputtering target having In content of 0.1 at $\%$. The (002) peak intensity of this sample is remarkably stronger than that of sample A (GZO) that deposited from the target having no In atoms. Figure 1(a) also shows that adding a small amount of In atoms leads to significant improvement in the crystalline quality of GZO film, but a further increase in the In atoms leads to decreases in the intensity of the (002) peak. As shown in Figure 1(a), the (002) peak intensity drastically diminishes upon gradually increasing In content in target up to 1 at $\%$ while keeping the sum of $(\mathrm{Ga}+\mathrm{In})$ atoms at content of $5 \mathrm{at} \%$. This indicates that, only at appropriate concentrations, the combination of $\mathrm{Ga}$ and In impurities can enhance the crystallization of $\mathrm{ZnO}$ film.

To assess the crystalline quality and the change in lattice, the (002) peak positions and the grain sizes of the samples were examined in Figure 1(b). The (002) peak positions of all samples (B-E) move to a lower $2 \theta$ value compared with that of pure $\mathrm{ZnO}$ thin film $\left(34.43^{\circ}\right)$, sputtered under the same condition (Figure 1(a)). According to the Bragg law, the decrease in the Bragg angle $2 \theta$ reflects the increase in interplanar spacing. This can be explained by the substitution of $\mathrm{In}^{3+}$ ion on the $\mathrm{Zn}^{2+}$ sites or the presence of interstitial In atoms in the $\mathrm{ZnO}$ lattice and the larger ionic radius of $\mathrm{In}$ atoms $(0.081 \mathrm{~nm})$ compared with that of $\mathrm{Zn}$ atoms $(0.074 \mathrm{~nm})$ [15]. In contrast, many other research groups reported the decrease of the $c$-axis lattice parameter due to the increase in the number of substituted $\mathrm{Ga}^{3+}$ ions into $\mathrm{Zn}^{2+}$ sites in $\mathrm{ZnO}$ materials [15-18]. From the above consideration, it can be deduced that even with a small amount of additional In atoms (sample B), the lattice stress due to the In atoms may have a more significant effect than that due to the $\mathrm{Ga}$ atoms. As seen in Figure 1(b), the grain size, estimated using Scherrer's formula, significantly increases from $58 \mathrm{~nm}$ in sample A to $83 \mathrm{~nm}$ in sample B but drastically decreases to $31 \mathrm{~nm}$ in sample E upon further increasing In content. By comparison, an average grain size in the range of $30-50 \mathrm{~nm}$ of GZO films has been reported by several authors [16, 18, 19]. This indicates that the combination of 0.1 at $\%$ In and 4.9 at $\% \mathrm{Ga}$ atoms in $\mathrm{ZnO}$ target can improve the grain size as compared with the 5 at\% Ga-doped $\mathrm{ZnO}$. However, the increase in In content more than 0.3 at $\%$ leads to the decrease in grain size. We suggest that the improved crystalline quality of sample B as shown in Figure 1 is due to the role of In impurities. MikiYoshida et. al. [20] found that the (002) plane of $\mathrm{ZnO}$ was abruptly enhanced as only doped with critical content of 


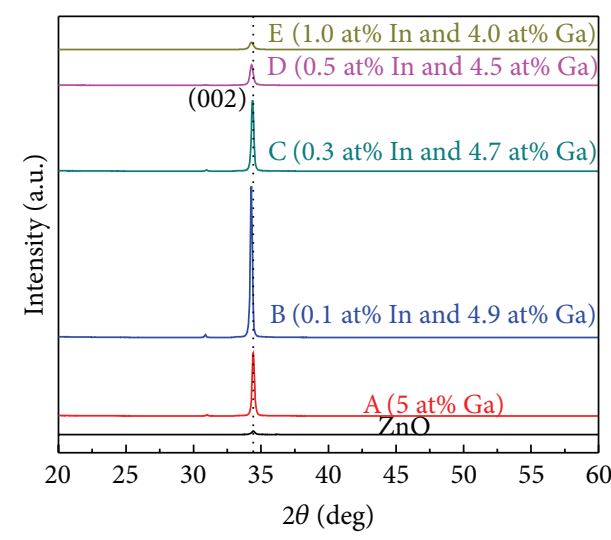

(a)

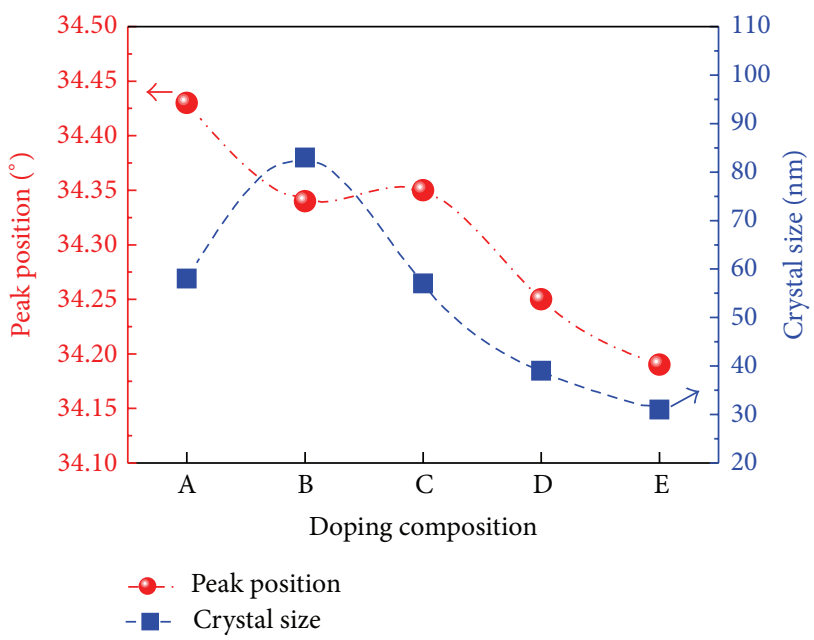

(b)

FIGURE 1: (a) X-ray diffraction patterns and (b) (002) peak position and crystal size of the as-deposited IGZO films with various In and Ga contents in targets.

In atoms in the range of $0.5-1$ at $\%$ and sharply decreased with further increase in In atoms. The same characteristics in XRD patterns have been obtained by other research groups [21-23]. Up till now, the crucial role of In impurities in enhancing crystalline quality of $\mathrm{ZnO}$ lattice has not been clearly understood. With the relatively small decrease of Ga content as in sample B, its effect on the crystallization of $\mathrm{ZnO}$ film is not significant. Thus, the main role in promoting the crystallization of $\mathrm{ZnO}$ is ascribed to a small amount of additional In atoms. In addition, a small In content in sample B is not able to play a role as efficient dopants, providing conductive charge carriers. Consequently, the exact combination of a minor In and major $\mathrm{Ga}$ impurities can enhance both the conductivity and crystalline quality of $\mathrm{ZnO}$ film in this study. The essential role in providing conductive carriers originated from major Ga-dopant substitution in the $\mathrm{Zn}$ sites. The crystalline degradation of films upon further increase of In atoms $(\geq 0.3$ at $\%)$ can be attributed to the large lattice distortion in $\mathrm{ZnO}$ film, as shown in Figure 1(b), due to considerable substitution or interstitial In atoms into $\mathrm{ZnO}$ lattice.

The electrical properties of as-deposited and postannealed samples, including carrier concentration, mobility, and resistivity, are shown in Figure 2. For as-deposited samples, the lowest resistivity of $2.5 \times 10^{-4} \Omega \cdot \mathrm{cm}$ is obtained with sample $B$. The increase in resistivity of samples from $2.5 \times 10^{-4} \Omega \cdot \mathrm{cm}$ to $7.5 \times 10^{-4} \Omega \cdot \mathrm{cm}$ corresponds to the increase in In content and decrease in the corresponding Ga content as shown in samples B-E in Figure 2(a). In comparison with sample A having no In atoms, it can be seen that, with the additional 0.1 at $\%$ In atoms in target, the resistivity of sample $\mathrm{B}$ is lowered. This demonstrates that the correct combination of $\mathrm{Ga}$ and In atoms can enhance the conductivity of $\mathrm{ZnO}$ sample. The highest values of carrier concentration and mobility are also observed in sample B. The mobility increases from 20 (sample A) to $25 \mathrm{~cm}^{2} / \mathrm{V} \cdot \mathrm{s}$ (sample B) with the presence of In atoms and decreases to $15 \mathrm{~cm}^{2} / \mathrm{V} \cdot \mathrm{s}$ (sample E) with further increase of In atoms. The increase or decrease in mobility is substantially related to the crystal quality of films. In relation to the XRD results shown in Figure 1(a) and the crystal size shown in Figure 1(b), it can be recognized that the behavior of the mobility is consistent with that of the XRD pattern and crystal size. It is known that while the carrier concentration in $\mathrm{ZnO}$ materials can be controlled by the solubility of dopants, the mobility is limited by the scattering of the charge carriers in the lattice [24]. Many electron scattering mechanisms occur in $\mathrm{ZnO}$ materials such as scattering by ionized impurities, neutral centers, thermal vibrations of lattice, structural defects (vacancies, dislocation, and stacking faults), and grain boundaries, depending on the carrier concentration and crystal quality of the material [24]. Enhancing the mobility is often associated with an improvement of crystallinity, diminishing defects in the lattice, or reduction in the ionized impurity scattering $[16,25]$. In this case, the enhanced mobility of sample B compared with that of sample A can be achieved by increasing the crystalline grain size, as proved in Figure 1(b), resulting in a decrease in the quantity of grain boundaries in the lattice, leading to limited grain boundary scattering. In contrast, the strengthening of the grain boundary scattering upon the decreased crystal size of other samples (samples C-E) compared with that of sample B led to diminished mobility. For postannealed samples as shown in Figure 2(b), it is noticed that the resistivity of samples $B$ and $C$ retains a low order of $10^{-4} \Omega \cdot \mathrm{cm}$, while that of other samples strongly increases. The lowest value of $7.2 \times 10^{-4} \Omega \cdot \mathrm{cm}$ is obtained for sample $B$. This suggests that a small amount of In atoms in GZO films can limit degradation of resistivity upon annealing in air. In comparison with the electrical characteristics of asdeposited films as shown in Figure 2(a), a strong decrease occurs in carrier concentration while the mobility further increases for all films. The decrease in carrier concentration is 


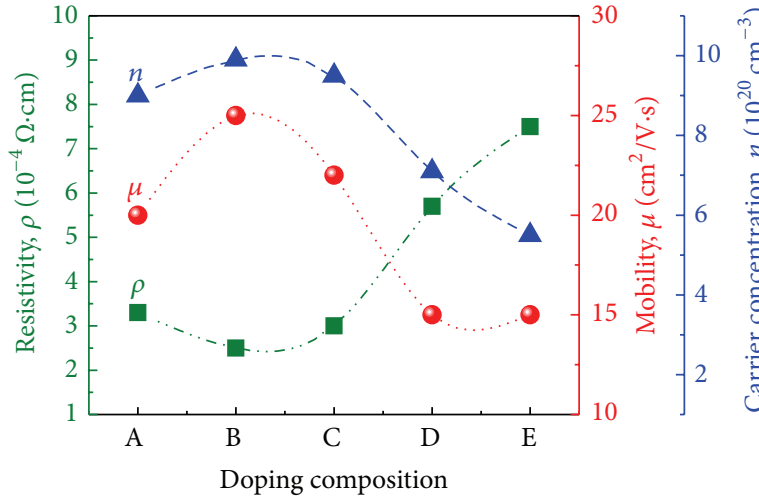

(a)

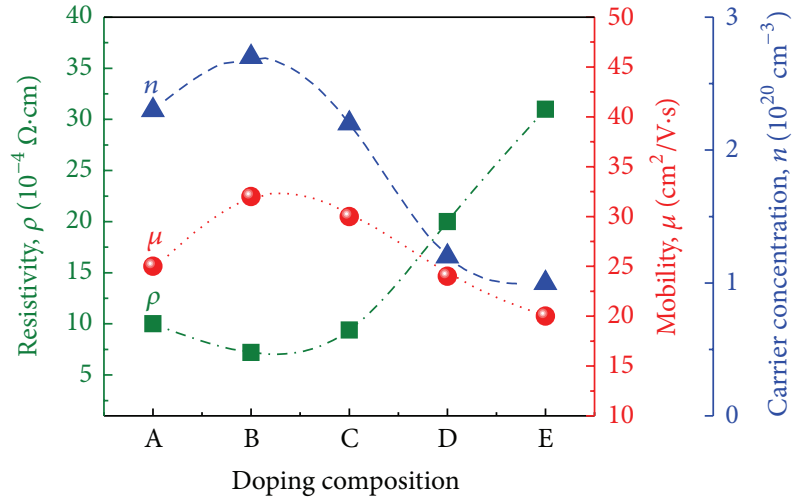

(b)

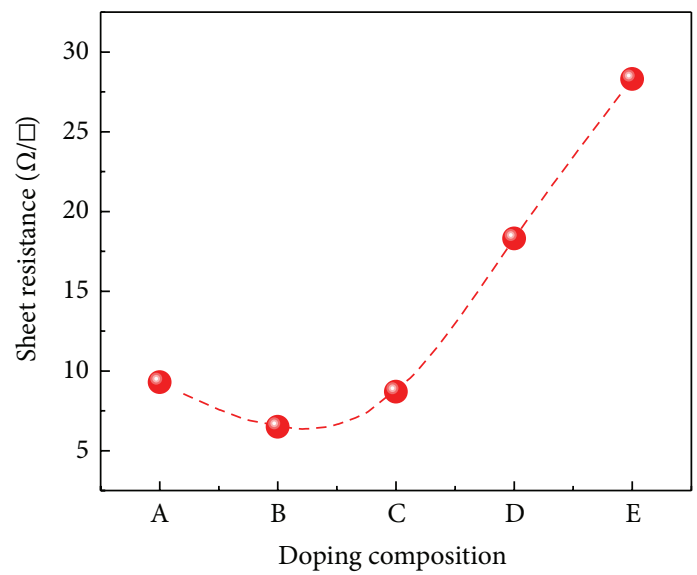

(c)

Figure 2: Carrier concentration, mobility, and resistivity of (a) as-deposited samples and (b) postannealed samples and (c) sheet resistances of postannealed samples with various In and Ga contents in targets.

often attributed to penetration of oxygen atoms on vacancies or to desorption of interstitial atoms upon annealing at high temperature. For transparent conducting oxide (TCO) thin films, one of the main reasons for degradation of conductivity upon annealing is ascribed to the unavoidable decrease in carrier concentration; the increase in mobility can therefore compensate for the degradation of carrier concentration, leading to the stability of resistivity. Thus, as shown in Figure 2(b), the increase from $27 \mathrm{~cm}^{2} / \mathrm{V} \cdot \mathrm{s}$ to a high value of $32 \mathrm{~cm}^{2} / \mathrm{V} \cdot \mathrm{s}$ in the mobility of sample B after heat-treatment at $500^{\circ} \mathrm{C}$ can compensate for the decrease in carrier concentration, resulting in significantly limiting the degradation of resistivity, while the increase to a lower value of mobility of other samples, especially in comparison with GZO (A sample), which is without In dopants, inefficiently compensates for the corresponding decrease in carrier concentration.

Figure 3 shows the typical optical transmittances for two as-deposited and postannealed A and B films. It is observed that the transmittance of initial films is nearly $80 \%$ in visible range, but less than $60 \%$ in NIR $(800-1100 \mathrm{~nm})$. With initial high carrier concentration in the range of 9$10 \times 10^{20} \mathrm{~cm}^{-3}$, significantly decreased transmittance in NIR

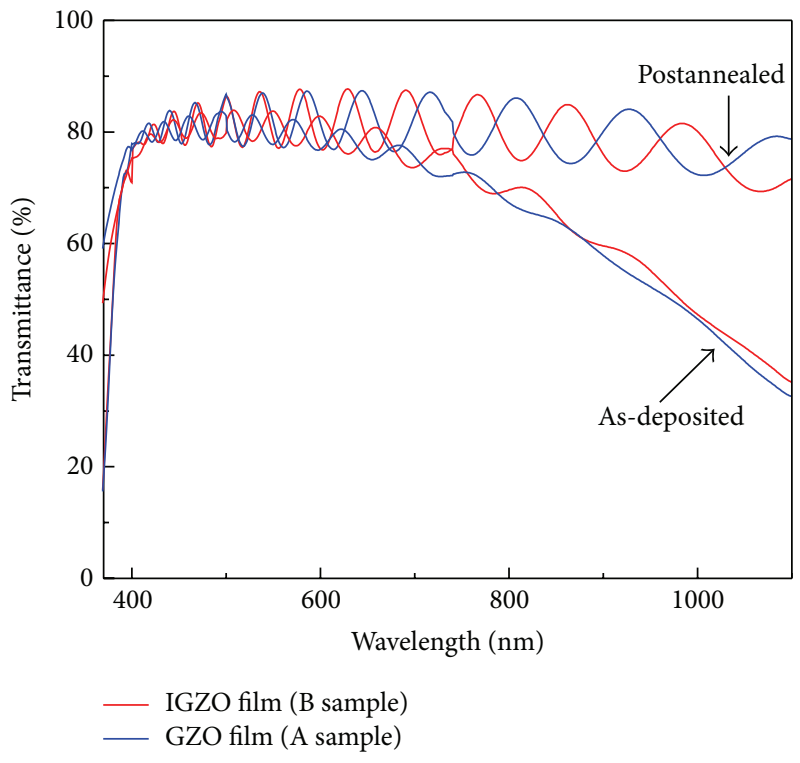

FIgUre 3: Transmittance of GZO (A sample) and IGZO (B sample) films in both cases of as-deposited and postannealed samples. 
is attributed to strong free-carrier absorption. Consequently, to enhance the transmittance in NIR, all films were annealed in air for $2 \mathrm{~h}$ at $500^{\circ} \mathrm{C}$. It is clear that, after annealing, the transmittance significantly increases in both visible and NIR region. For example, the transmittance in $800-1100 \mathrm{~nm}$ is less than $60 \%$ for as-deposited sample, but nearly higher $80 \%$ for postannealed sample. According to the Drude model, the free-carrier absorption primarily induces low transmission in the visible and NIR region of transparent conductive oxides (TCOs). Thus, the lower carrier concentration of two samples causes enhancing transmittance of films in this range. In addition, it should be noticed that although having the same high transmittance, the IGZO film shows lower resistivity compared with GZO film.

From the above structural and optoelectronic results, we can preliminarily conclude that the presence of a small amount of In dopants (0.1 at\%), combined with mainly Gadopants (4.9 at\%) in the $\mathrm{ZnO}$ target, can significantly improve the crystallization of sputtered $\mathrm{ZnO}$ films. Through annealing process, especially, the high transmittance in both visible and NIR region associated with low resistivity of film is expected for well using as front electrodes in TFS-SCs. In respect of applying in front side of TFS-SCs, the required criteria for the optoelectronic properties of the transparent conducting electrodes depend on the structure and the absorber material of the solar cell. For example, with respect to amorphous silicon absorber layer, a high transmittance in visible range $(400-750 \mathrm{~nm})$ is sufficient, while in case of $\mu \mathrm{c}-\mathrm{Si}: \mathrm{H}$ or "micromorph" tandem solar cells, a high transmittance in all ranges from 400 to $1100 \mathrm{~nm}$ is necessary. This case demands TCOs to have a reasonable carrier concentration while still retaining a low resistivity or sheet resistance [26]. Normally, for efficient transport of generated current, the TCOs must have less than $10 \Omega / \square$ sheet resistance and high transmittance over $80 \%$ in both ranges to increase the light reaching the absorber layer $[26,27]$. The most popularly used TCOs for TFS-SCs have been $\mathrm{SnO}_{2}$ :F (FTO) films due to their high transparency and electrical conductivity. The commercially available FTO coated glass with a sheet resistance of $6-8 \Omega / \square$ has been efficiently used in high performance thin film solar cell structures $[28,29]$. In comparison with commercial FTO substrate, we believe that, with low sheet resistance of $6.5 \Omega / \square$ as shown in Figure 2(c) and high transmittance in all ranges from 400-1100 nm shown in Figure 3, the IGZO film can be an alternative to FTO films as front-contact for high efficiency $\mu c-S i: H$ or "micromorph" tandem solar cell structure.

To define the presence as well as different effects of In element on optoelectronic properties of GZO films, compositional analysis of postannealed B-E samples was carried out by EDX measurement. The obtained EDX spectra are nearly the same for B-E samples. By way of illustration, the EDX spectrum of postannealed $\mathrm{C}$ sample is shown in Figure 4 . The higher-intensity peaks, emitted by $\mathrm{Zn}, \mathrm{O}$, and Ga elements, clearly show that $\mathrm{ZnO}$ film was doped with high Ga concentration. Some lower-intensity peaks confirm the existence of small amount of In element in the film. The inset table listed In contents in the samples from B to E calculated from EDX spectra for comparison. It is noted that In contents in samples from B to E are different from those in targets

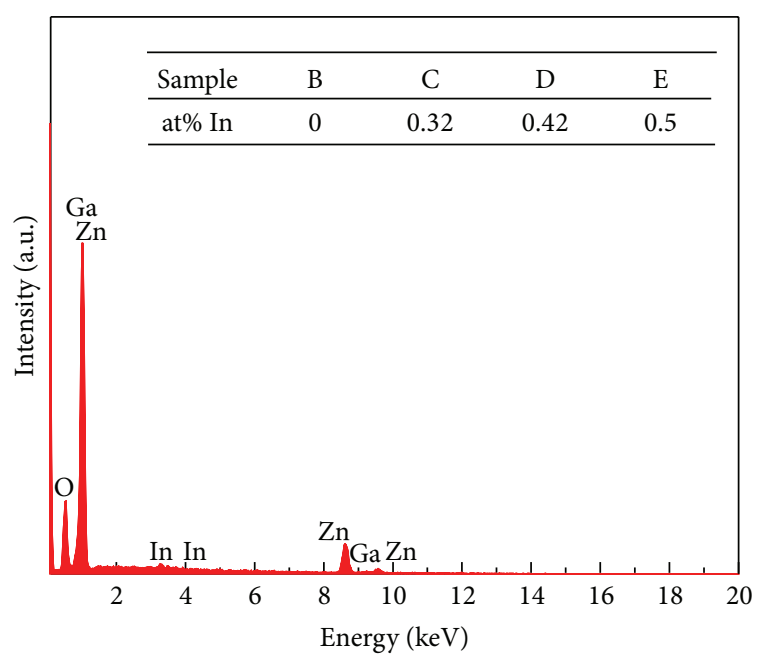

FIGURE 4: The EDX spectrum of postannealed C sample. The inset shows the atomic percentages of Indium element in postannealed samples from B to E calculated from EDX spectra.

from B to E, respectively. It is also noted that there is no In content recorded by EDX measurement in sample B. Now, there are two relevant questions that need further discussion. The first one is that, owing to the atomic-mass difference, the sputtering rates of different elements are not the same. In addition, many other factors, such as different atomicadsorption, atomic-desorption, atomic chemical-reactions, and atomic surface-diffusion on substrates, also affect the atomic contents in deposited films. Therefore, the In contents in samples, in this case, are not identical to those in targets. The second question is that it is probable that too small amount of In atoms in sample B could be detectable by EDX measurement. It is very reasonable because the effects of In presence in sample $B$ on improving the structural and electrical properties of GZO films were confirmed by XRD patterns and Hall measurement as shown in Figures 1(a) and 2, respectively. To distinctly ascertain these effects of additional Indium atoms, B samples and A samples were deposited on glass substrates from targets with and without In atoms, respectively. For comparison, both samples B and A have the same thicknesses that range from 500 to $2000 \mathrm{~nm}$ and both are annealed up to $450^{\circ} \mathrm{C}$ in air. The optoelectronic and structural properties of films are presented in Figures 5 and 6 , respectively. While the high transmittances in both visible and NIR region, as shown in Figure 5(b), are similar, the carrier concentrations and mobility of IGZO films, as indicated in Figure 5(a), are all higher than those of GZO films at every thickness, leading to lower resistivities of IGZO films compared with those of GZO films. The higher carrier mobility of IGZO films can be caused by improved crystallization as shown in Figure 6, in which XRD-peak intensities of IGZO films are slightly higher than those of GZO films at each film thickness. Throughout considered results, although a small amount of In atoms in sample B is not easy to be probed by EDX measurement, their effect on improving optoelectronic and structural properties of GZO 

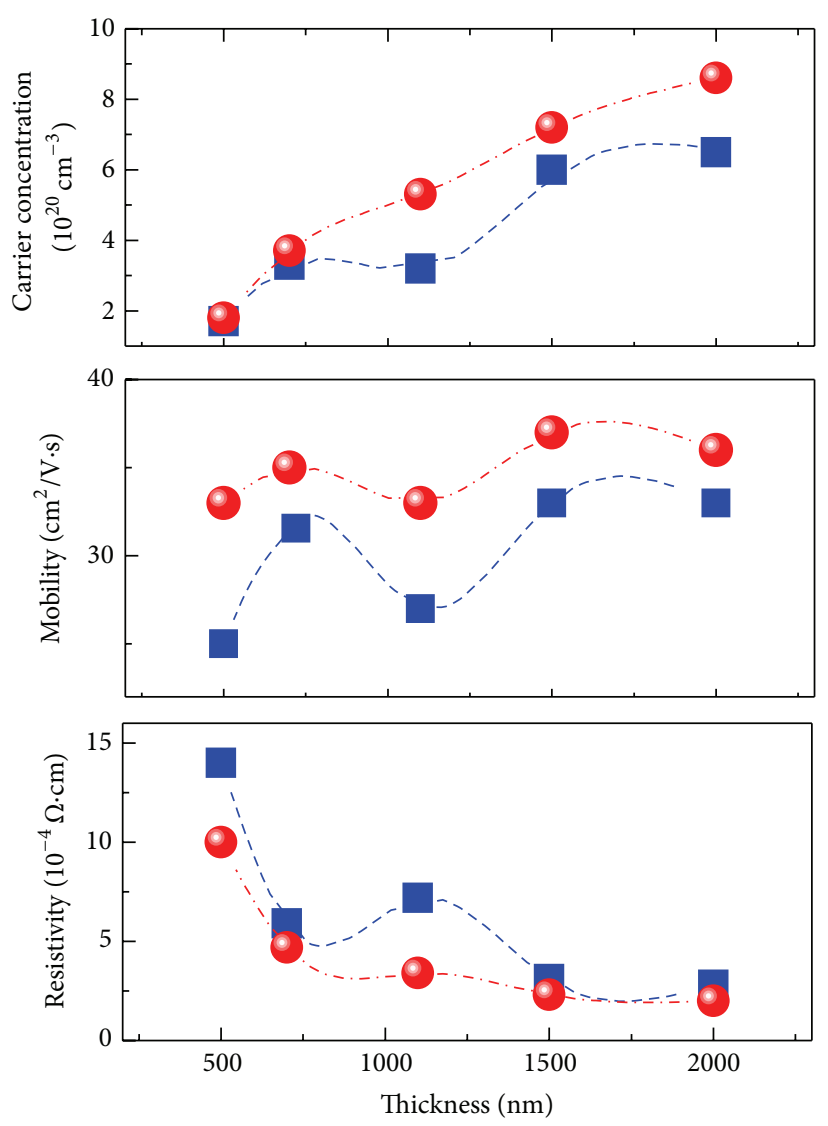

- GZO film

-. - IGZO film

(a)

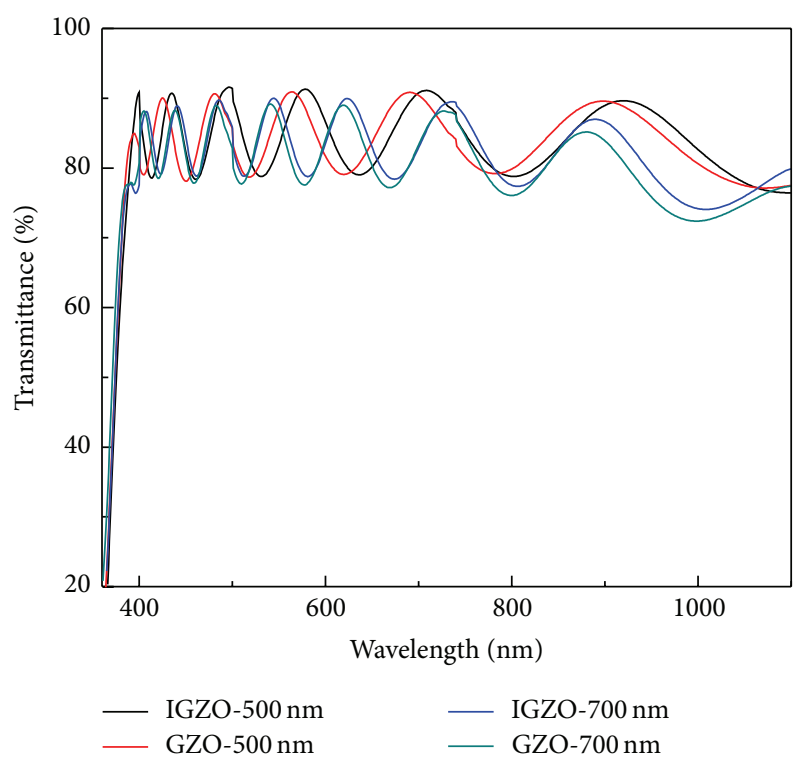

(b)

FIGURE 5: (a) Carrier concentration, mobility, and resistivity of postannealed GZO (A sample) and IGZO (B sample) films at various film thicknesses from 500 to $2000 \mathrm{~nm}$ and (b) transmittance of postannealed GZO (A sample) and IGZO (B sample) films with two film thicknesses of $500 \mathrm{~nm}$ and $700 \mathrm{~nm}$ for comparison.

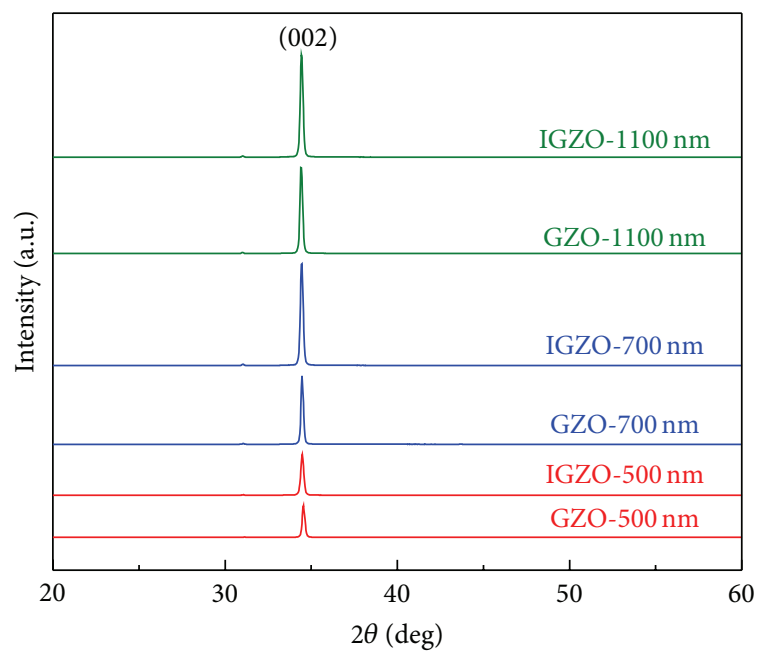

FIGURE 6: X-ray diffraction patterns of postannealed GZO (A sample) and IGZO (B sample) films with various film thicknesses for comparison.

film is clearly demonstrated. Thus, we suggest that a small addition of In impurities can, without changing the transmittance, enhance the electrical property of GZO films, which is suitable to be used as a front-contact layer in TFS-SCs.

Although the measured data reveal clear enhancement of structural and optoelectronic properties of IGZO films in comparison with GZO films, the exact role of the additional In atoms has not been clearly verified in this study. Further investigation should be made to identify the position of In atoms in host $\mathrm{ZnO}$ lattice for deeply understanding their important role. To be fully aware of the aspects leading to enhanced conductivity and improved crystallization of the IGZO films, the role of both In and Ga impurities has to be considered. For that reason, there is much room for further studies of the codoping concept in order to have a better comprehension of the basic mechanisms governing the structural and optoelectronic properties of $\mathrm{ZnO}$ material.

\section{Conclusion}

The effect of the addition of different Indium-impurity contents on optoelectronic and structural properties of GZO films is investigated. With small Indium addition of 0.1 at $\%$ in sputtering target, the deposited IGZO thin films have better quality than the GZO film counterparts. Through annealing process in the range of $450-500^{\circ} \mathrm{C}$, the IGZO films have high transmittance over $80 \%$ in both visible and NIR region and have low sheet resistance of less than $10 \Omega / \square$. Although the role of In element has not clearly been defined in this study, with obtained results referred above, it is apparent that the IGZO thin film can be well applied as front electrode in thin film silicon solar cells.

\section{Conflict of Interests}

The authors declare that there is no conflict of interests regarding the publication of this paper. 


\section{References}

[1] T. Matsui, C.-W. Chang, and M. Kondo, "Effect of illuminationinduced space charge on photocarrier transport in hydrogenated microcrystalline $\mathrm{Si}_{1-x} \mathrm{Ge}_{x}$ p-i-n solar cells," Applied Physics Letters, vol. 91, Article ID 102111, 2007.

[2] S. T. Chang, M. Tang, R. Y. He, W.-C. Wang, Z. Pei, and C.-Y. Kung, "TCAD simulation of hydrogenated amorphous siliconcarbon/microcrystalline-silicon/hydrogenated amorphous silicon-germanium PIN solar cells," Thin Solid Films, vol. 518, no. 6, pp. S250-S254, 2010.

[3] J.-E. Lee, D. Kim, K. H. Yoon, and J.-S. Cho, "Enhanced performance of flexible nanocrystalline silicon thin-film solar cells using seed layers with high hydrogen dilution," Journal of Nanoscience and Nanotechnology, vol. 13, no. 12, pp. 7891-7894, 2013.

[4] J. Park, S. M. Iftiquar, S. Lee et al., "Reduction of tail state on boron doped hydrogenated amorphous silicon oxide films prepared at high hydrogen dilution," Journal of Nanoscience and Nanotechnology, vol. 13, no. 12, pp. 7826-7833, 2013.

[5] J. Jung, K. Ha, J. Cho et al., "Enhancing light trapping properties of thin film solar cells by Plasmonic effect of silver Nanoparticles," Journal of Nanoscience and Nanotechnology, vol. 13, no. 12, pp. 7860-7864, 2013.

[6] H. Park, J. Lee, Y.-J. Lee et al., "Inserted layer of AZO thin film with high work function between transparent conductive oxide and p-layer and its solar cell application," Journal of Nanoscience and Nanotechnology, vol. 13, no. 10, pp. 7116-7118, 2013.

[7] T. Söderström, F.-J. Haug, X. Niquille, and C. Ballif, “TCOs for Nip thin film silicon solar cells," Progress in Photovoltaics: Research and Applications, vol. 17, no. 3, pp. 165-176, 2009.

[8] C.-S. Tian, X.-L. Chen, J. Ni et al., "Transparent conductive $\mathrm{Mg}$ and $\mathrm{Ga}$ co-doped $\mathrm{ZnO}$ thin films for solar cells grown by magnetron sputtering: $\mathrm{H}_{2}$ induced changes," Solar Energy Materials and Solar Cells, vol. 125, pp. 59-65, 2014.

[9] C. Agashe, O. Kluth, J. Hüpkes, U. Zastrow, B. Rech, and M. Wuttig, "Efforts to improve carrier mobility in radio frequency sputtered aluminum doped zinc oxide films," Journal of Applied Physics, vol. 95, no. 4, pp. 1911-1917, 2004.

[10] T. Ghosh and D. Basak, "Enhanced mobility in visible-to-near infrared transparent Al-doped ZnO films," Solar Energy, vol. 96, pp. 152-158, 2013.

[11] M. Netrvalova, I. Novotny, L. Prusakova, V. Tvarozek, and P. Sutta, "Influence of deposition regime on physical properties of gallium doped zinc oxide films," Vacuum, vol. 86, no. 6, pp. 707710, 2012.

[12] C. Guillén and J. Herrero, "Optical, electrical and structural characteristics of $\mathrm{Al}: \mathrm{ZnO}$ thin films with various thicknesses deposited by DC sputtering at room temperature and annealed in air or vacuum," Vacuum, vol. 84, no. 7, pp. 924-929, 2010.

[13] K. Tao, Y. Sun, H. Cai, D. Zhang, K. Xie, and Y. Wang, "Deposition Ga-doped ZnO films on PEN substrate at room temperature for thin film silicon solar cells," Applied Surface Science, vol. 258, no. 16, pp. 5943-5946, 2012.

[14] J.-I. Nomoto, Y. Nishi, T. Miyata, and T. Minami, "Influence of the kind and content of doped impurities on impurity-doped ZnO transparent electrode applications in thin-film solar cells," Thin Solid Films, vol. 534, pp. 426-431, 2013.

[15] K. Jung, W.-K. Choi, S.-J. Yoon, H. J. Kim, and J.-W. Choi, "Influence of substrate temperature on the electrical and optical properties of Ga-doped $\mathrm{ZnO}$ thin films fabricated by continuous composition spread," Ceramics International, vol. 38, no. 1, pp. S605-S608, 2012.

[16] Y.-D. Ko, K.-C. Kim, and Y.-S. Kim, "Effects of substrate temperature on the Ga-doped $\mathrm{ZnO}$ films as an anode material of organic light emitting diodes," Superlattices and Microstructures, vol. 51, no. 6, pp. 933-941, 2012.

[17] S. Mukhopadhyay, S. Gowtham, R. Pandey, and A. Costales, "Theoretical study of small clusters of indium oxide: $\mathrm{InO}, \mathrm{In}_{2} \mathrm{O}$, $\mathrm{InO}_{2}, \mathrm{In}_{2} \mathrm{O}_{2}$," Journal of Molecular Structure: THEOCHEM, vol. 948, no. 1-3, pp. 31-35, 2010.

[18] F. Wu, L. Fang, Y. J. Pan et al., "Effect of annealing treatment on structural, electrical, and optical properties of Ga-doped $\mathrm{ZnO}$ thin films deposited by RF magnetron sputtering," Thin Solid Films, vol. 520, no. 2, pp. 703-707, 2011.

[19] S. S. Shinde, P. S. Shinde, Y. W. Oh, D. Haranath, C. H. Bhosale, and K. Y. Rajpure, "Structural, optoelectronic, luminescence and thermal properties of Ga-doped zinc oxide thin films," Applied Surface Science, vol. 258, no. 24, pp. 9969-9976, 2012.

[20] M. Miki-Yoshida, F. Paraguay-Delgado, W. Estrada-López, and E. Andrade, "Structure and morphology of high quality indiumdoped $\mathrm{ZnO}$ films obtained by spray pyrolysis," Thin Solid Films, vol. 376, no. 1-2, pp. 99-109, 2000.

[21] F. Paraguay D., J. Morales, W. Estrada L., E. Andrade, and M. Miki-Yoshida, "Influence of $\mathrm{Al}, \mathrm{In}, \mathrm{Cu}, \mathrm{Fe}$ and $\mathrm{Sn}$ dopants in the microstructure of zinc oxide thin films obtained by spray pyrolysis," Thin Solid Films, vol. 366, no. 1-2, pp. 16-27, 2000.

[22] A. Hafdallah, F. Yanineb, M. S. Aida, and N. Attaf, "In doped $\mathrm{ZnO}$ thin films," Journal of Alloys and Compounds, vol. 509, no. 26, pp. 7267-7270, 2011.

[23] D. H. Kim, N. G. Cho, H. G. Kim, and W.-Y. Choi, "Structural and electrical properties of indium doped zno thin films fabricated by RF magnetron sputtering," Journal of the Electrochemical Society, vol. 154, no. 11, pp. H939-H943, 2007.

[24] H. Liu, V. Avrutin, N. Izyumskaya, Ü. Özgr, and H. Morkoç, "Transparent conducting oxides for electrode applications in light emitting and absorbing devices," Superlattices and Microstructures, vol. 48, no. 5, pp. 458-484, 2010.

[25] E. Fortunato, L. Raniero, L. Siva et al., "Highly stable transparent and conducting gallium-doped zinc oxide thin films for photovoltaic applications," Solar Energy Materials \& Solar Cells, vol. 92, no. 12, pp. 1605-1610, 2008.

[26] J. Müller, B. Rech, J. Springer, and M. Vanecek, "TCO and light trapping in silicon thin film solar cells," Solar Energy, vol. 77, no. 6, pp. 917-930, 2004.

[27] H. M. Yates, P. Evans, D. W. Sheel, S. Nicolay, L. Ding, and C. Ballif, "The development of high performance $\mathrm{SnO}_{2}: \mathrm{F}$ as TCOs for thin film silicon solar cells," Surface and Coatings Technology, vol. 213, pp. 167-174, 2012.

[28] M.-S. Choi, Y.-J. Lee, J.-D. Kwon et al., "Effects of hydrogen plasma treatment on $\mathrm{SnO}_{2}$ :F substrates for amorphous $\mathrm{Si}$ thin film solar cells," Current Applied Physics, vol. 13, no. 8, pp. 15891593, 2013.

[29] C. Beneking, B. Rech, S. Wieder et al., "Recent developments of silicon thin film solar cells on glass substrates," Thin Solid Films, vol. 351, no. 1-2, pp. 241-246, 1999. 

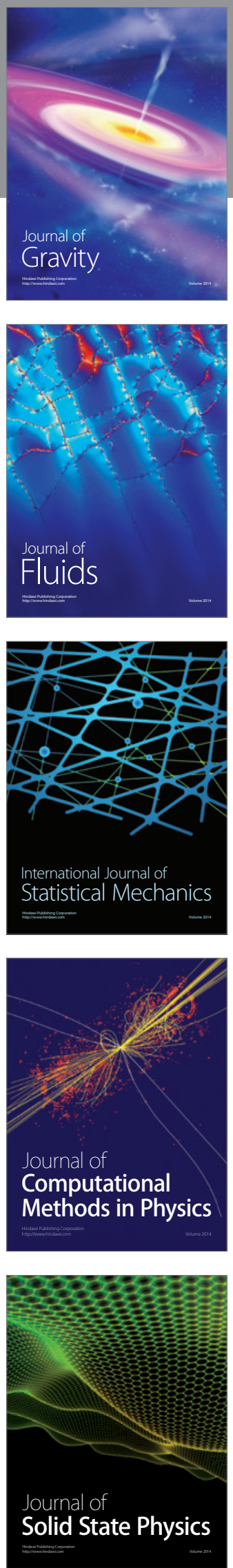

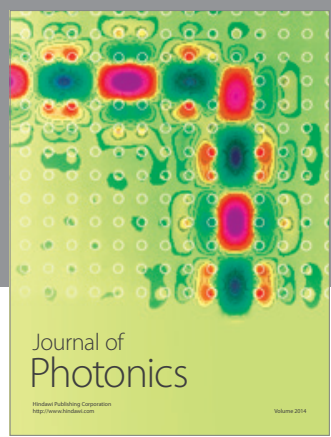

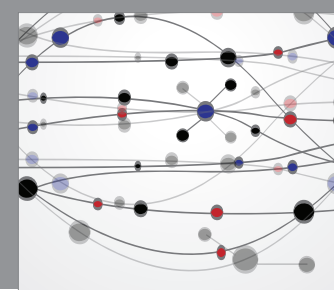

The Scientific World Journal

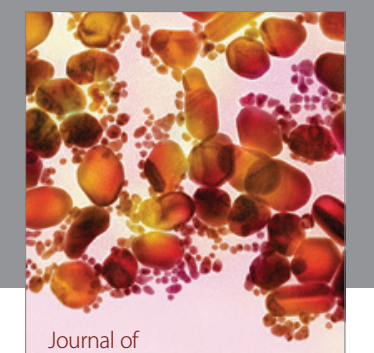

Soft Matter
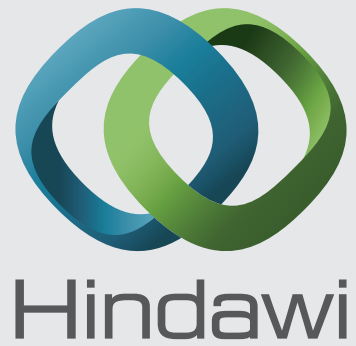

Submit your manuscripts at

http://www.hindawi.com
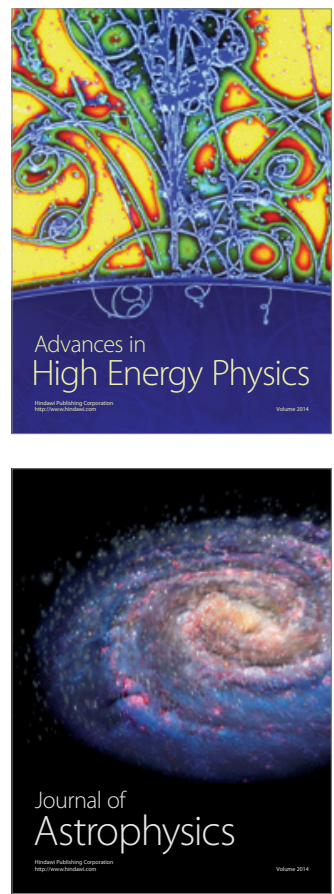
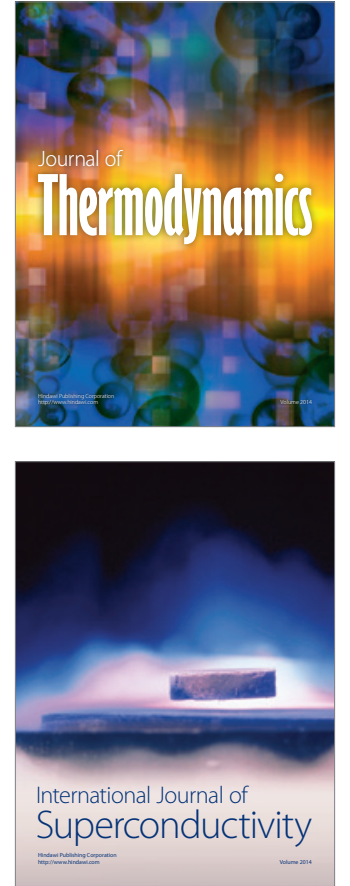
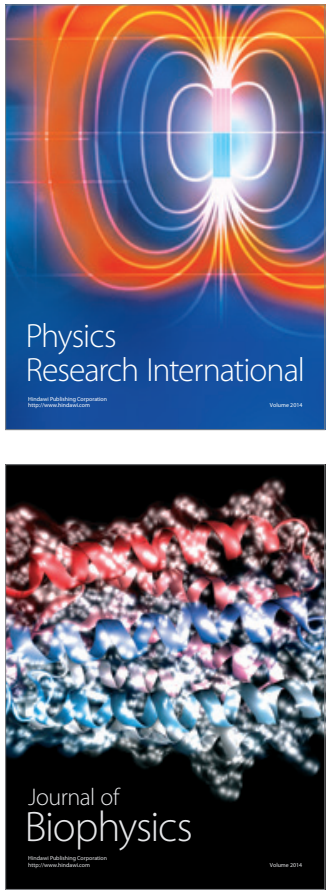
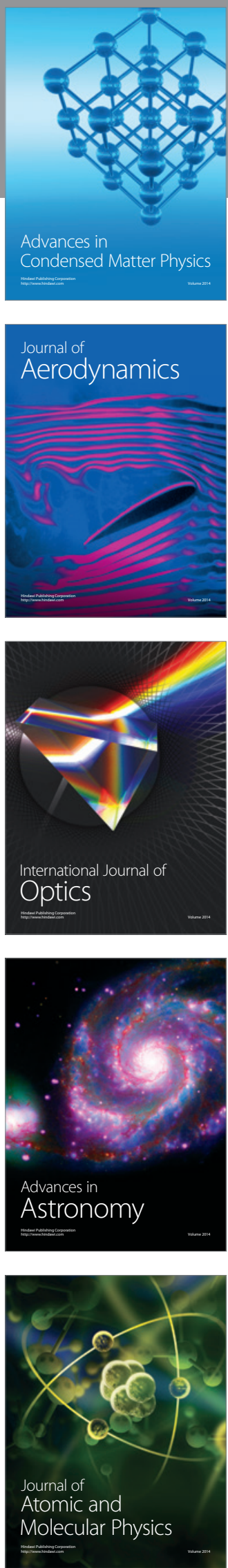